\title{
REFLEXIONES A PROPÓSITO DEL CAMBIO DE OBISPO EN LA DIÓCESIS SAN JOSÉ DE TEMUCO'
}

Pbro. Juan Leonelli L.

Es de público conocimiento que los obispos, de acuerdo a las disposiciones de la propia Iglesia, al cumplir 75 años de edad deben presentar su renuncia al gobierno de la diócesis. ${ }^{2}$ Precisamente esta es la situación que se vive en la Iglesia de Temuco, porque el pasado 27 de abril Monseñor Sergio Contreras Navia cumplió 75 años de edad y, tal como lo recomienda el $\mathrm{ClC}$, presentó su renuncia al Papa Juan Pablo II. Como todos los años, también esta vez nos reunimos en torno a la Eucaristía, en una sencilla pero significativa ceremonia para celebrar su cumpleaños; sólo que en esta oportunidad se podia percibir en el ambiente un dejo de tristeza porque -aunque nada se dijo-era evidente que se trataba del primer acto de su alejamiento definitivo de esta diócesis a la cual ha servido por más de 23 años. ${ }^{3}$

A partir de entonces, ef inminente cambio de obispo en nuestra diócesis pasó a ser el terna obligado de conversación en los diversos ámbitos de la vida de la Iglesia diocesana. Pero no sólo en las instancias eclesiales, sino tambièn en aquellos ambientes de la sociedad donde hay personas que sienten un profundo aprecio y gratitud hacia el obispo Sergio Contreras. En efecto, diversos grupos e instituciones, incluidas las autoridades regionales, junto con lamentar la partida de don Sergio comienzan a expresar en forma pública y privada una gran admiración y

N.del E.: Este articulo fue escrito en mayo cuando aùn no se realizaba el nombramiento de Monseñor Manuel Camilo Vial como nuevo obispo de Temuco.

El cese de funciones de los obispos no es automático al cumplir 75 años de edad. Sin embargo, a todos se les ruega que presenten su renuncia al alcanzar dicha edad. En efecto, el código de derecho canónico señala expresamente: "Al Obispo diocesano que haya cumplido setenta y cinco años de edad se le ruega que presente la renuncia de su oficio al sumo pontifice. el cual proveera teniendo en cuenta todas las circunstancias" (CIC 401, 1)

3 Monseñor Sergio Contreras Navia tomó posesión de la diócesis de Temuco el 15 de enero de 1978, el mismo año que fue elegido Karol Wojtyla (16 de octubre) como obispo de Roma y, como tal, cabeza de la igiesia universal. 
gratitud hacia la persona y la incansable labor realizada por este pastor que ha presidido la Iglesia de Temuco bajo el lema episcopal: "no he venido a ser servido sino a servir".

De todos modos debemos reconocer que ante este hecho surgen variadas reacciones. La primera de ellas es que para muchos -entre los que me cuento- se nos hace dificil imaginarnos esta Iglesia sin su actual Pastor. Y tal reacción se explica simplemente porque para estas personas, tanto su adhesión a Cristo y su consecuente compromiso de vida cristiana, como su profundo respeto y reconocimiento a la labor pastoral y social que la Iglesia desarrolla en la región, son fruto de las orientaciones y de la impronta que les dio el obispo Sergio Contreras. En mi caso particular, se debe añadir otro elemento que explica el especial aprecio por la persona de don Sergio: la providencial coincidencia de que el mismo año de la llegada de Monseñor Contreras a la diócesis se produce mi ingreso al seminario; por lo tanto, todo el proceso de formación, ordenación sacerdotal y todo el servicio ministerial que he realizado hasta hoy ha tenido como referente la figura de don Sergio. En similares condiciones se encuentra la mayor parte de los sacerdotes de la diócesis de Temuco.

Otra natural reacción -justificada plenamente en este caso, según mi parecer- es que como se trata de un obispo que se ha convertido en un auténtico buen pastor y servidor de sus hermanos, y como tal ha determinado no sólo el peregrinar de la Iglesia de Temuco en los últimos años, sino que ha contribuido significativamente en la definición de las grandes lineas orientadoras de la Iglesia Católica chilena y latinoamericana, todavía tiene mucho que aportar; y por lo demás sus condiciones de salud se to permiten perfectamente. En este sentido, la pregunta más recurrente que surge en diversos ámbitos diocesanos, también en las instancias no eclesiales, es: ¿por qué don Sergio tiene que dejar el gobierno de la diócesis, si aún se le ve con energias y mantiene en buenas condiciones todas sus capacidades, además que todavia lo necesitamos?

Por todo lo que hemos señalado se justifica plenamente que este tema adquiera gran importancia en la vida de la Iglesia diocesana, sobre todo si tenemos presente que monseñor Sergio Contreras es el obispo que más tiempo ha permanecido en la conducción pastoral de la diócesis de Temuco (falta poco para que se cumplan 24 años) y, además, para varias generaciones es la primera experiencia de cambio de obispo que nos corresponde vivir. Se debe añadir también el hecho de que es la primera vez en la historia de esta diócesis que un obispo culmina en ella su ministerio pastoral; es decir, es el primer obispo que renunciará a la conducción de la diócesis porque ha cumplido 75 años de edad.

Pues bien, a propósito de este hecho que como hemos señalado constituye una experiencia única en la historia de nuestra diócesis, ofrecemos la siguiente reflexión. Comenzaremos por definir lo que en la Iglesia católica significa una diócesis y daremos una mirada a la historia de la diócesis de Temuco; luego abordaremos el tema acerca del rol que en la 
Iglesia cumple el obispo y presentaremos brevemente la figura de los obispos que han conducido a la Iglesia de Temuco durante sus escasos 75 años de existencia. Finalmente, para darle una perspectiva de futuro a nuestra reflexión, expondremos algunas de las caracteristicas humanas y pastorales del obispo que esperamos como pastor de nuestra Iglesia para los años venideros.

\section{A. ¿QUÉ ES UNA Diócesis?}

Históricamente las "diócesis" eran divisiones administrativas (una especie de provincias) del imperio romano y la Iglesia adoptó el término para indicar el territorio o la "porción del pueblo de Dios cuyo cuidado pastoral se encomienda al Obispo." En este sentido, podriamos dar la razón a los comentarios de tipo periodistico que muchas veces identifican una diócesis con una determinada región, aun cuando no siempre sus respectivas jurisdicciones coinciden. En nuestro caso particular, la región de la Araucania tiene dos obispos, uno con sede en Temuco y el otro en Villarrica, por lo tanto no se puede hablar del obispo de la región de la Araucania. Tampoco todos los obispados alcanzan la categoria de Diócesis; existen otras estructuras eclesiales como las Prelaturas. cuya atención pastoral puede ser encomendada a un prelado o un abad y los Vicariatos Apostólicos, que corresponden a la etapa de iniciación de la Iglesia en un territorio en misión y el obispo que los gobierna no lo hace directamente sino en nombre del Papa. ${ }^{5}$

Por este motivo -y en mayor sintonia con el Concilio Vaticano II-, en lugar de diócesis se prefiere utilizar la expresión: Iglesias particulares. Esta expresión es más adecuada sobre todo para exponer una verdad sobre la Iglesia que muchas veces se desconoce. Se trata de que en cada una de las Iglesias particulares o diócesis está presente la Iglesia de Jesucristo, aquella que el Concilio define como "sacramento universal de salvacion", esto es: "instrumento de la unión intima con Dios y de la unidad de todo el género humano." No es como piensan algunas personas, que una lglesia depende de otra (con la lógica de que las más pequeñas son menos importantes y dependen de aquellas a las que se le atribuye mayor importancia); la Iglesia universal es fruto de la comunión de todas las Iglesias particulares "en las cuales y desde las cuales existe... verdaderamente está presente y actúa la Iglesia de Cristo una, santa, católica y apostólica".

En este sentido, una determinada diócesis o Iglesia particular no puede ser considerada "una parte" de la Iglesia, en el sentido de parcialidad

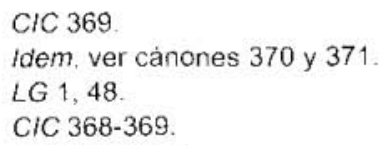


o de una realidad incompleta, sino que es la misma Iglesia universal que como afirma Pablo VI- se "encarna en las Iglosias particulares constituidas de tal o cual porción de humanidad concreta". Esto quiere decir que por su naturaleza sacramental, ia Iglesia de Cristo se constituye en verdadero signo de salvación para ia humanidad, siempre y cuando valore la diversidad cultural y se encarne en cada una de las culturas. Precisamente en este proceso de inculturación se comprende mejor la auténtica relación entre Iglesia universal e Iglesias particulares; asi lo comprende el cardenal Paul Poupard, presidente del Pontificio Consejo para la Cultura, al señalar que "un criterio fundamental sin el cual no hay verdadera inculturacion de la fe es la universalidad de la Iglesia y la comunión entre las Iglesias particulares"."

La relación entre la Iglesia, comprendida en su dimensión global y universal, y las Iglesias particulares, que debiera estar bastante clara entre nosotros que conformamos el pueblo de Dios, es todavia "hoy una cuestión candente, motivo de intensos debates" a nivel teológico. "El cardenal Kasper advierte que el gran peligro que puede existir en este tema es pretender salvaguardar la universalidad de la Iglesia a partir de una consideración abstracta, fundada en el primado de la Iglesia universal sobre las Iglesias particulares (es precisamente io que se cuestiona de la postura del cardenal Ratzinger); esto significaria no reconocer que la Iglesia es una realidad histórica concreta que se construye desde la realidad local, por eso precisamente a las diócesis también se les denomina "Iglesias locales".

Kasper fundamenta su posición a partir de la Sagrada Escritura para afirmar que desde los primeros tiempos de la Iglesia, es la comunión de las Iglesias particulares, es decir, todas ellas juntas, lo que constituye la Iglesia universal. "La lglesia primitiva se desarrolló a partir de comunidades locales. Cada una presidida por un obispo: la única lgiesia de Dios estaba presente en cada una de ellas... La Iglesia particular no es ni una provincia ni un departamento de la Iglesia universal; es la Iglesia en un lugar determinado.

\section{EN 62 .}

9 Paiabras del cardenal Paul Poupard durante una conferencia sostenida en la Universidad "La Sapienza" de Roma, el 26 de mayo de 1998. Continúa el cardenal Poupard: Las iglesias particulares ho son una foderacion con divcrsidad de credos. que por solidaridad crean unos vinculos do relacionos más o monos protundas. Ellas tienen un clemento comim que les haco vivir una dimension profunda de comunion. de tat manera que son la unica iglesia, en medio de culturas distintas. Las lglesias particularcs hacen prcsente sin agotarla a la Iglesia universal. y son tales porque tanto en Roma. como en la India, como en América Latina o en ctialquera de tos continentes proclaman la misma y úmica fe. El misterio de la Encamacion se conviertc como tal en paradigma de una evangelización inculturada. es of unico Señor Josucristo que toma carne en las diversas culturas (cfr SD. 230)", www.mercaba.org/OBISPOS

Estas expresiones corresponden al cardenal Walter Kasper, quien en un reciente articulo que trata sobre la "Relación entre la Iglesia universal y las Iglesias particulares" refuta la posición de otro cardenal, el Prefecto de la "Congregación para la Doctrina de la $\mathrm{Fe}$ "Joseph Ratzinger, quien "ha enfocado of problema dosde un punto do vista meramente abstracto y teórico. sin tener on cuenta situaciones y experiencias pastorales concretas". MENSAJE 500 (2001) 32 y 34 
El obispo local no es un delegado del Papa sino alguien enviado por Jesucristo. quien le confió una responsabilidad personal". "

Afortunadamente. en el contexto latinoamericano los obispos han precisado muy bien la relación entre Iglesia universal e Iglesias particulares: "En la Iglesia particular. formada a imagen de la Iglesia Universal. se encuentra y opera verdaderamente la Iglesia de Cristo que es una, santa, católica y apostólica. Es una porción del Pueblo de Dios. definida por un contexto socio-cultural más amplio. en el cual se encarna".

En efecto, las Iglesias particulares lejos de constituir un peligro para la unidad de la Iglesia. se caracterizan por la comunión entre ellas y por la misión de prolongar la acción evangelizadora de Cristo que comparten; y de este modo enriquecen a la Iglesia universal. La unidad de la Iglesia se expresa en la valoración de la diversidad, del mismo modo que "el cuerpo es uno y tiene muchos miembros, y todos los miembros del cuerpo. por muchos que sean. no forman más que un solo cuerpo" (1 Co 12.12ss); y "la evangelización pierde mucho de su fuerza y de su eficacia. si no toma en consideración al pueblo concreto al que se dirige. si no utiliza su "lengua". sus signos y simbolos. si no responde a las cuestiones que plantea. no llega a su vida concreta"."

Pero la diócesis por si sola no es la única expresión de la Iglesia. De gran importancia para una diócesis son las parroquias éstas se comprenden juridica y administrativamente como comunidades de fieles que conforman un determinado territorio estable dentro de una Iglesia particular y su pastor propio es el párroco." En este sentido, el Papa Juan Pablo II define la parroquia como "una comunidad de fe y una comunidad orgánica en la que el párroco. que representa al obispo diocesano. es el vinculo jerárquico con toda la Iglesia particular". "' Desde una perspectiva más pastoral y en contexto latinoamericano los obispos definen la parroquia como lugar de encuentro, en el sentido de que "acompaña a las personas y familias a lo largo de su existencia. en la educación y crecimiento de su fe. Es centro de coordinación y de animación de comunidades. de grupos y movimientos. Aqui se abre más ol horizonte de comunión y participación" "i."

Tampoco las parroquias agotan en si mismas la expresión de una Iglesia particular. Sin embargo, el aporte más significativo que las Iglesias latinoamericanas hacen a la Iglesia universal, signo de su propia vitalidad,

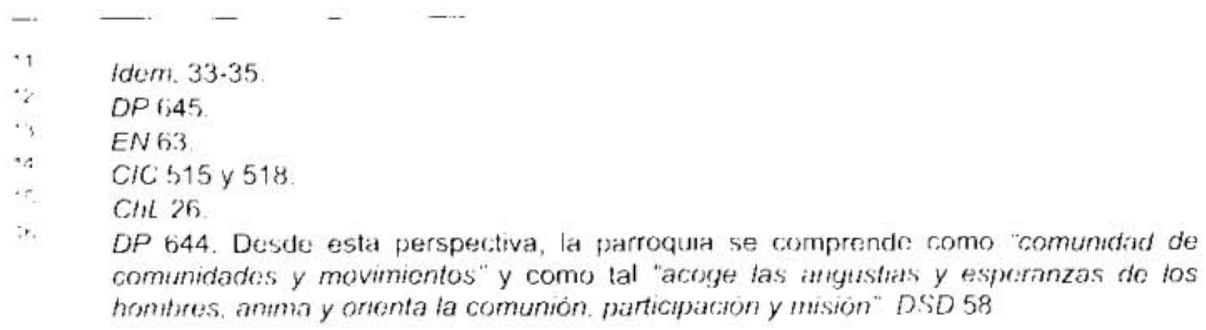


son las Comunidades Eclesiales de Base. Las CEB son al fruto más inmediato del Concilio Vaticano II, que defino la Iglesiat como Pueblo de Dios. lo cual permite? valorar y estimular la participacion activa de los laicos.

Estas comunidades que despuès del Concilio "fiorecen por todas partes en la Iglesia" se asomejan a las comunidades cristianas primitivas y se convierten en instrumentos privilegiados de evangelización. "nacen de la necesidad de vivit todavia con mas intonsidad ta vida de la lglesia. o del deseo y de la bisqueda de uma dimonsion mas humana que dificilmente pueden ofrecer las comulichdes oclesiales mas grandes".

\section{B. Sobre la Diócesis de Temuco}

\section{Algunos datos históricos sobre la creación de la diócesis de Temuco}

El 18 de Octubre del Año Santo de: 1925. el Papa Pio XI crea varias diocesis en Chile. entre cllas la "Diocesis de San José de Temuco" que se desprende de Concepción y cuyo territorio comprende gran parte de la IX Región de la Araucania. Se exliende desde el Rio Renaico. por el norte. hasta el Rio Cautin. por el sur. De manera que su territorio abarca la totalidad de la provincia de Malleco y gran parto de la provincia de Cautin." Al momento de ser creada esta diócesis ya existian varias purroquias que dependian de la diocesis de Conceprion. La primera parroquia que se estableció dentro del territorio que comprende la actual diócesis de Temuco fue la de Angol. alrededor del año 1880. pocos años más tarde en 1892. Mons Plácido Labarca. obispo de Concepción. crea la parroqua "San José de Temuco" y su primer párroco fue don Ricardo Sepúlveda."

Respecto a este hecho fundacional de la lgglesia particular de Temuco. señalaremos dos datos de cierla curiosidad históricia y. por lo mismo, resultan ser interesantes: el primero de ellos se relaciona con el Papa Pio XI

17

1.

19

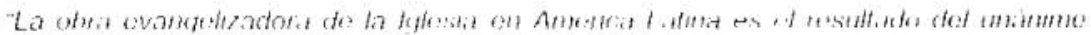

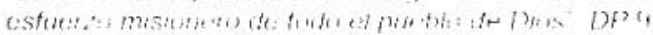

FN 58

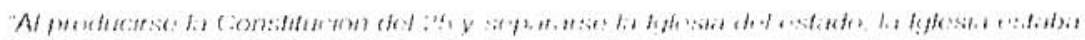

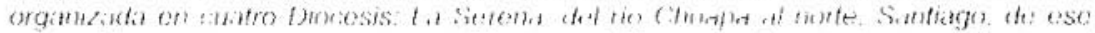

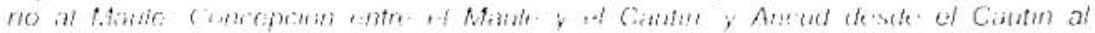

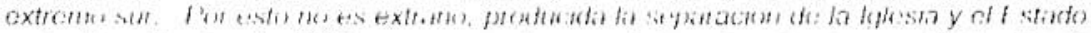

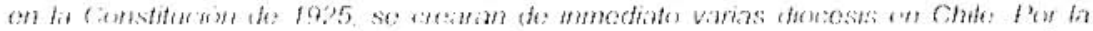

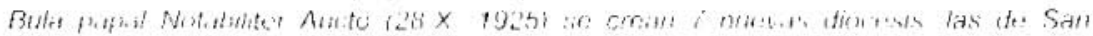

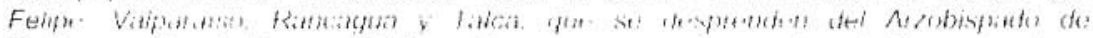

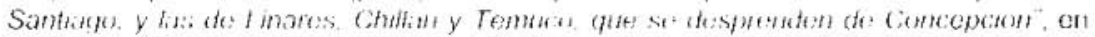

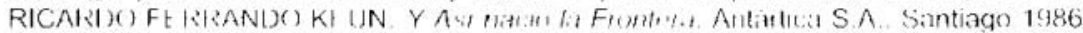
p. $5 / 15 / 3$

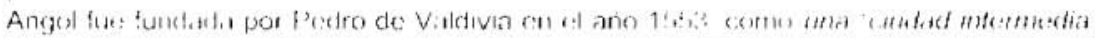

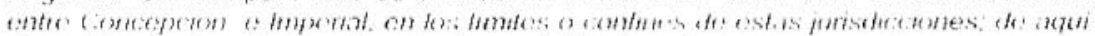

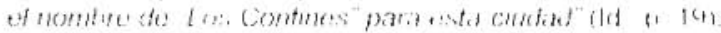


que creó la diócesis de Temuco y, el segundo, se refiere a la diócesis de Concepción. desde la que se desprendió este nuevo obispado.

\section{a) En relación al Papa Pio $X I^{21}$}

Ambrogio Damiano Achille Ratti nació el 31 de mayo de 1857 en Desio -cerca de Milán. Italia- procedente de una familia de la clase media industrial (su padre fue director de una fábrica en la industria de la seda). Se le reconoce como un gran promotor de las ciencias y de la investigación cientifica; por lo mismo, con gran dedicación dirige las bibliotecas Ambrosiana y Vaticana. En 1918. aprovechando su gran habilidad para los idiomas, el Papa Benedicto XV lo envia a Polonia, primero como visitador apostólico, y al año siguiente como Nuncio. En 1921 el Papa Benedicto XV lo llamó de vuelta a Italia, nombrándolo arzobispo de Milán y le otorgo el capelo cardenalicio. Sólo seis meses después (el 6 de febrero de 1922) el cardenal Achille Ratti seria elegido para suceder a Benedicto XV en la Sede de Pedro, tomando el nombre de Pio XI.

Al Papa Pio XI le correspondió guiar a la Iglesia en medio de un mundo sacudido y herido por la guerra. Su deseo más entrañable era el de lograr la paz duradera, trabajando para que el Sen̈or Jesús llegase a ser el centro y el principio de toda la sociedad. "Pax Christi in regno Christi" (La paz de Cristo en el reino de Cristo) expresaba el "lema pontificio", y con este lema buscaba motivar a todos los hijos de la Iglesia para que aportasen, cada cual en su particular ámbito de competencia, a la construcción de un nuevo orden social según los principios que para la convivencia en sociedad posee la Iglesia. Fue por este deseo que en diciembre de 1925 instituia la fiesta de Cristo Rey con la publicación de su enciclica Quas primas.

Entre las numerosas enciclicas de Pio XI destacan la referente a la moral matrimonial Casti connubi, de 1930 y la relativa al orden social Quadragesimo anno, publicada en mayo de 1931, en la que reafirma y profundiza las enseñanzas sociales de su predecesor el Papa León XIII. Sin embargo, la solución de la Hamada "cuestión romana", con la firma de los pactos lateranenses. puede ser considerada una de las decisiones concernientes a politica interna de la Iglesia más importantes del papado; esto es: el tratado en el que se reconoce a la Ciudad del Vaticano como estado soberano y el Concordato entre la Santa Sede y el Estado italiano, mediante el cual se garantiza que la Iglesia pueda nombrar libremente a los obispos y el Estado reconoce valor legal y efecto civil al matrimonio religioso, entre otros beneficios. Ello acontece durante el pontificado de Pio XI. Ciertamente por sus grandes obras, de hecho "los historiadores concuerdan en considerarlo uno de los papas más significativos de la historia de la Iglesia"." Se le conoce como el Papa de las misiones por su gran apoyo a la

Ver recuadro titulado "Un hermann del Papa en Capitan Pastene" al final dell presente articulo.

GELMI JOSEF. I Papi. Bıblioteca Universale Rı/zoli, Mılano 13993. p. 263. 
acción misionera de la Iglesia, siendo la "Acción Católica" la obra predilecta de su pontificado. es también el creador de varias obras en Roma como el Instituto de Arqueologia Cristiana, la Pontificia Academia de la Crencias y la Radio Vaticana entre otras.

\section{b) Respecto a la diócesis de Concepción}

Pasamos ahora a analizar algunos acontecimentos historicos en torno a la diocesis de Concepción. de la cual se desprende la diocesis de Temuco. Para ello debemos partir señalando que durante el siglo XVI en el territorio de la Gobernación de Chile existieron por varios años sólo dos jurisdicciones eclesiásticas. El Papa Pio IV. a petición del rey Felipe II. creo en el año 1561 el obispado de Santiago el cual se desprende de la diocesis de Lima y abarca la totalidad del territorio chileno y parte del territorio argentino (las provincias de Cuyo y Tucuman). Apenas dos anos mas tarde. el mismo Papa crea, a partir de la diocesis de Santiago, un nuevo obispado en territorio chileno: la diócesis de La Imperial que abarca desde el rio Maule hasta el extremo sur del pais.

Pues bien. la primera consecuencia de este hecho para nuestra diócesis es que la sede del obispo de La Imperial estuvo ubicada en la primera ciudad fundada por Pedro de Valdivia en la Araucania el año 1552. en el territorio que actuaimente ocupa la ciudad de Carahue. El nombre de La Imperial le viene dado en honor del emperador de la epoca. Carlos V." De este modo. debemos señalar que en la zona de la Araucania, dentro del territorio que comprende la actual diocesis de Temuco, 400 años antes de que se creara esta diócesis. existió por varios años una sede episcopal. La diócesis de "La Imperial" que tenia como patrono a San Miguel Arcangel, ${ }^{\text {* }}$ fue sede episcopal entre el 17 de septiembre de 1568 (año que tomó posesión el obispo de la Imperial) hasta el año 1603, cuando la sede del obispo -por razones que señalaremos más adelante- se trasladó a Penco y finalmente a Concepción. razón por la cual comenzo a llamarse definitivamente "diócesis de Concepcionn".

En la diocesis de La Imperial existian varios lugares poblados, que probablemente fueron tambièn las primeras parroquias: Chillin. Concepción. Arauco. Angol. Villarrica. La Imperial. Valdivia. Osorno. Ancud y Castro. se construyó un Hospital con el nombre de San Juliản y ol primer Seminario en

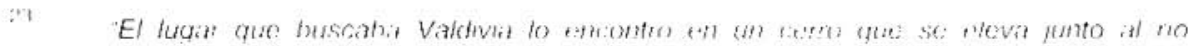

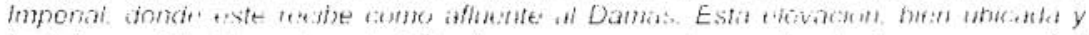

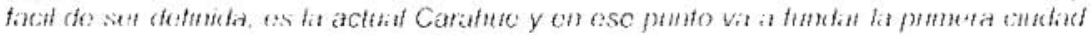

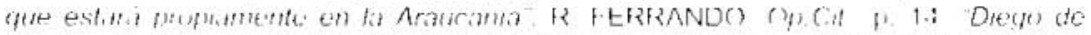

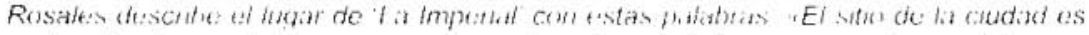

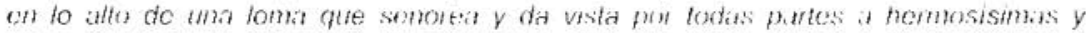

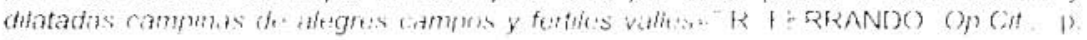
15

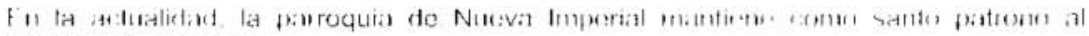

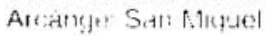


Chile que debia formar los futuros sacerdotes para toda la Colonia". La ciudad de La Imperial progresó rápidamente y llegó a ser "la más insigne ciudad de este reino", como señala Gaspar Chacón. "De no ser destruida es muy probable que se habria constituido en el centro de la Colonia; no por nada estuvo muy cercana la posibilidad de que en La Imperial se instalara la primera universidad en territorio chileno. ${ }^{27}$

El primer obispo de La Imperial, que es también el primer obispo consagrado que hubo en territorio chileno. fue el franciscano Antonio de San Miguel Avendaño y Paz. quien después de ser consagrado en Lima en 1567 tomó posesión de la diócesis de La Imperial. Este obispo se caracteriza por ser un decidido defensor de los indigenas. denunciando los graves excesos cometidos por los conquistadores contra ellos. "Desde su llegada. fue el alma de la defensa dol mapuche. Puso todo su cariño y su poder como Pastor contra los abusos con los indigenas, amenazando en ciertos casos con la excomunion a algunos encomenderos y gobernadores... al Rey manifiesta por carta que el peligro permanente de sublevacion so debe al exceso de trabajo y al mal trato que se les da"." También tuvo una destacada participación en el Concilio de Lima, convocado por el arzobispo Santo Toribio de Mogrovejo en el año 1582. A su regreso desde Lima convocó a un Sinodo en su diócesis, pero no se tiene precisión de la fecha ni tampoco poseemos documentación sobre el particular."

El obispo fray Antonio de San Miguel, considerado uno de los prelados más grandes de su tiempo, con más de 80 años de edad fue llamado a tomar posesión de la prestigiosa diócesis de Quito y falleció precisamente en

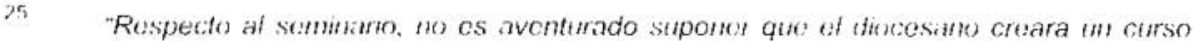
de estudios ectesiasticos amenas se hoo cargo do su sodo. puque chtre hos anos 1571 y 1582 ordent varus sactudotes . Ks preshiterus ordenados por of prmer obispo te? La hmpenal. nvangehzador del star de: Chife furon màs o menus vointe". FIDEL

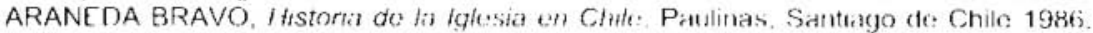
p. 29

26 R FERRAND(). Op Cit , is 16, ff p.56;8

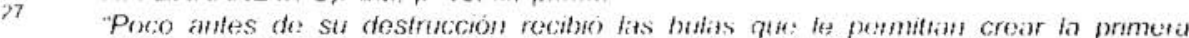
Universutad en Chite" Id. p. 16. "Hay quimes phemsin (fit: si t:sta calamiad so

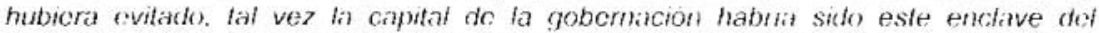

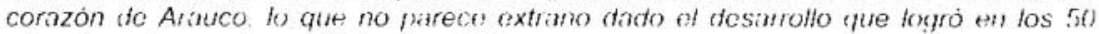
atos de vida que alcimlo" Item, p. 5699

Fray Autonio de Sam Miguel "fue el primer Obispo ausatyrato tue hubo en Chile" (ldem, p. 16). Era ef primes obsipo consagrado que prsaba tiona chulena y tenm fama de santo. razones poderosas que justificabin ol grandioso rucibimichto que fe ficierm sus diocesanos". F ARANEDA, Op Cit. p. 27. Hay que senalir que el obispo telecto te Santiago don IRodrigo Gonzalez Mamolejo, quien podria haber sido el prumero, "numio

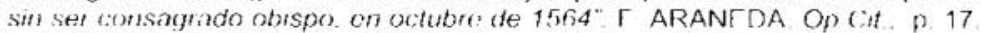

R. FERRANDO, Op. Cit. p 568, tn la misma linea FIDEl ARANI DA afirma que ios "indios cran hermanus en Jestmisto. que como it lates hermanos debian trillatos $y$

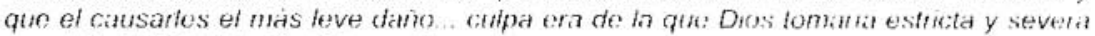
cisents", ARANEDA, Op.Cit. p. 27. 
Ecuador. mientras se dirigia a su nueva diócesis. Sólo dos obispos más aicanzaron a ocupar la sede episcopal de La Imperial. En 1587 fue nombrado obispo fray Agustin de Cisneros. a los 67 años de edad: quien no pudo emprender grandes obras debido a su delicado estado de salud. por lo que renunció en 1595 y falleció al año siguiente en La Imperial. Entre la muerte de este obispo y el nombramiento del dominico fray Reginaldo de Lizárraga en 1599. como tercer obispo de la diocesis, se produjo "la gran sublevación mapuche producida luego de la muerte del Gobernador Martin Onez de Loyola. en diciembre de 1598. Esta sublevacion termino con todo to que se habia hecho on la araucania y dejo en ruinas. que no se volvieron a levantar. a Imperial"."

A fines del ano 1602. cuando finalmente pudo llegar a la zona el tercer obispo de la Imperial, fray Reginaldo de Lizárraga, se encontró con la sede episcopal practicamente devastada y las ciudades desoladas. importantes obras como el Seminario habian desaparecido y costaria mucho restablecerlas. En estas condiciones comenzó a reorganizar la diócesis y una de las primeras acciones que realizo fue el traslado de la sede episcopal de La Imperial a las cercanias de Concepción (Penco). el 7 de febrero de 1603. "Lo cual no es extraño ya que Concepción habia sido siempre uno de los centros poblados más importantes del territorio chileno. incluso habia sido causa de litigios entre Santiago y La Imperial.

Desde entonces. la diócesis de La Imperial desapareceria definitivamente, pero permanece viva en la memoria de los historiadores que se interesan por conocer la región de la Araucania y en la experiencia de una Iglesia que al igual que su Señor se manifiesta concretamente -más bien dicho se encarna- en los diversos momentos y acontecimientos de la historia humana. La Iglesia valora la historia. porque es a través de los acontecimientos historicos que ella se va configurando como el pueblo que peregrina tras las huellas del Maestro: por eso precisamente. a partir de este año. La Imperial ha sido incluida "entre las sedes episcopalos titulares. al mismo modo de las sedes del mundo antiguo que ya no oxisten "." Esto significa que desde ahora un obispo de la Iglesia. de cualquier parte del mundo. podrá ser titular de la diócesis de La Imperial. De hecho. el Papa Juan Pablo Il acaba de nombrar como "titular de la diócesis de La lmperial" a monseñor Ricardo Ezzali quien deja la diócesis de Valdivia para

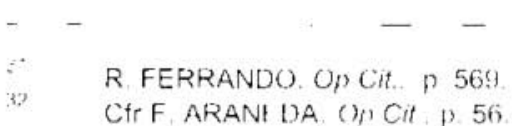

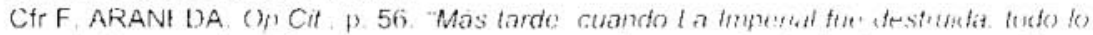

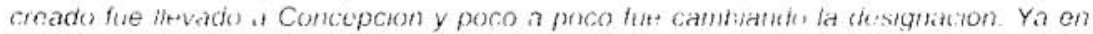

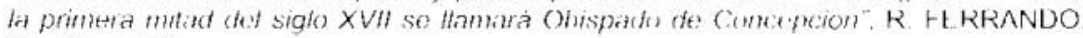
Op. Cll p. 16

Carta del Nuncio Apostóluco en Chile diriguda al obispo de Teunuco monsenor Sergio Contreras $N$ ion fecha 21 de febrero de 2001. en IGLESTA DE TEMAUCO 37 (2001) 4 En la leglesiat existen solo dos denominaciones parat los utispus los diocesanos a tos

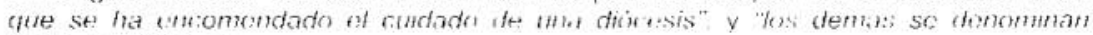
titulares". CIC 376
} 
desempeñarse como obispo auxiliar del cardenal Errázuriz en la Iglesia de Santiago.

\section{Visión socio-cultural de la diócesis de Temuco ${ }^{34}$}

La diócesis de Temuco se encuentra ubicada en pleno corazón de la Araucania, por ello su formación está muy ligada a la historia de las luchas del siglo XVI, especificamente a la guerra de Arauco sostenida por la conquista española, la posesión del territorio de la Frontera por los mapuche y el periodo posterior denominado "pacificación" que ha estructurado la configuración actual de la zona. Como hemos visto, el gran levantamiento del pueblo mapuche, que se realiza a fines del siglo XVI, destruyó literalmente la diócesis de La Imperial; desde entonces, se realizó el éxodo hacia la zona de Concepción y la Iglesia en la región dejó de tener una presencia orgánica; la labor pastoral entre los siglos XVII y XIX la realizaron principalmente los misioneros franciscanos, jesuitas y capuchinos.

Hoy la Diócesis es el $60 \%$ de la Novena Región que tiene 883 mil habitantes, de los cuales 538 mil son urbanos y 334 mil rurales. El $26 \%$ es mapuche, es decir, unos 230 mil habitantes. Existe también un importante numero de descendientes de colonos europeos y chilenos que siguen llegando de otras regiones; y, por cierlo, la mayoria de los habitantes han nacido en esta región.

Otro fenómeno, igualmente interesante para tener en cuenta, es el rápido crecimiento de la ciudad de Temuco, la que a la fecha concentra más del $30 \%$ de la población regional, con una tasa media de crecimiento del $2.36 \%$ para el decenio 1982-1992, mientras que en el pais es sólo del 1.55 $\%$ para el mismo periodo. Esta situación ubica a Temuco entre las ciudades medianas de más acelerado crecimiento de América Latina. De más está decir que Temuco es el principal centro poblado de la Región y el único que supera los 50 mil habitantes; y esto sumado a su calidad de Capital regional constituye un polo de atracción natural, lo que origina una marcada migración de habitantes de otras comunas y un constante flujo de población flotante en busca de nuevas alternativas de trabajo y mejoras en sus condiciones de vida, lo cual trae consigo una serie de problemas sociales.

Sin duda que el principal problema que tiene la Región de la Araucania es que aparece como la más pobre del pais, lo cual ha quedado reflejado en las Encuestas CASEN ${ }^{35}$ de los años 1996, 1998 y la última

34 Los antecedentes están tomados del documento del Il sinodo diocesano de la Iglesia de Temuco, 1994-1995: "Con Cristo caminamos al Tercer Milenio", nn 12-21; se han actualizado los datos conforme a los estudios más recientes.

35) Encuesta de Caracterización Socioeconomica Nacional. Este es un instrumento para conocer periódicamente la situación socioeconómica de los hogares y de la población nacional y regional. El análisis de las cifras y de los factores que causan la pobreza en la región corresponden al Sr. LUIS TORRALBO. Sccretario Ejecutivo de la Fundación 
realizada el año 2000. Esta última indica que la IX Región tiene un $32.7 \%$ de su población en situación de pobreza (276.247 personas), de los cuales el $11,1 \%$ (93.560 habitantes) vive en situación de indigencia. La gravedad de esta situación se ve acentuada al constatar que 15 de las 31 comunas de la Región, registran una pobreza superior al $40 \%$ en su población.

Ciertamente, son las comunas con mayor ruralidad y la vez aquellas con mayor presencia de comunidades mapuche, las que integran en su mayoria estas dolorosas cifras. A esta situación contribuyen, entre otros, los siguientes factores:

- La falta de industrias y fuentes de trabajo suficientes en la region.

- El éxodo de campesinos hacia las ciudades, provocado por la falta de expectativas y la oferta de los grandes consorcios forestales que les presionan a vender sus propiedades, a veces a muy bajos precios. Esto tiene como consecuencia una situación de desarraigo en el campesino que viene a incrementar los cinturones de marginalidad en la ciudad.

- Recursos naturales deteriorados o ausentes en las comunidades rurales mapuche. Como ejemplo de una larga lista se puede señalar que la gran mayoria de los predios de los agricultores mapuche no tienen derechos de agua constituidos y que sobre el $50 \%$ de los suelos de la provincia de Malleco se encuentran con una erosión de moderada a severa.

- La mayoria de los rubros silvoagropecuarios presentes en la región son de baja intensidad de uso de mano de obra, por ejemplo producir una hectárea de trigo en la actualidad requiere entre 2 y 4 jornadas por año, rangos en los cuales también se mueve la actividad forestal. esto obliga a migraciones ya sea a la ciudad o a la zona central para realizar actividades generadas por la fruticultura.

- La región no cubre su espacio territorial de manera uniforme con centros poblados de importancia, como lo hacen por ejemplo las regiones vecinas (VIII y X), lo cual genera dependencias e interacciones solo con la Ciudad Temuco, en los distintos ámbitos del desarrollo humano.

- La región no posee infraestructura para la salida de sus productos hacia otros paises. Io cual limita las posibilidades de exportación: solo et $0,1 \%$ de las exportaciones nacionales son de la IX Región.

- La inversión privada es bajisima, fluctuando entre el 1 y el $2 \%$ de 10 invertido en el pais por parte de los privados.

Todo lo anterior ha llevado a que el PIB (Producto Interno Bruto) Regional aporte con solo el $2.4 \%$ al PIB nacional, lo cual sumado a los bajos niveies de la educacion (alfabetizacion y años de estudio promedio) y a una

AFODFGAMA (Asnciación Fomento de Desarrollo Ganadero Mapuche). a quien agradecemos su valioso aporte. 
esperanza de vida al nacer inferior a los promedios nacionales, den lugar al peor Indice de Desarrollo Humano del pais.

\section{Visión de la realidad pastoral de la diócesis de Temuco ${ }^{36}$}

Con el propósito de dar a conocer cuál ha sido el caminar de esta Iglesia particular en sus escasos 75 años, especialmente durante el periodo que ha tenido como pastor al obispo Sergio Contreras Navia, indicaremos algunos aspectos - los que nos parecen más relevantes- de la vida pastoral, conscientes de que "somos depositarios de una tradición y esfuerzo evangelizador, en especial del Pueblo Mapuche; se nos confia el desafio siempre nuevo del anuncio del Reino, en la realidad histórico-cultural, que es nuestro patrimonio como un don concedido por Dios". ${ }^{37}$

Para la acción pastoral y evangelizadora que la diócesis realiza en su extenso territorio cuenta con 33 Parroquias, con sus correspondientes Comunidades Eclesiales de Base, articuladas en cuatro Decanatos. Existen en la actualidad unas 150 CEBs cuyo Animador es mapuche, lo cual garantiza que la comunidad viva su experiencia de fe cristiana valorando y utilizando, en lo posible, su propia lengua. Posee, además, diversos Organismos Diocesanos que ofrecen servicios pastorales especificos, tanto para el ámbito urbano como rural, especialmente en las áreas de la educación, la familia, los jóvenes, la catequesis, la formación de personas y ministerios, etc.

Para cumplir con su misión cuenta con un número apreciable de Sacerdotes y numerosos Diáconos Permanentes. A ellos se suman los varios cientos de laicos, comprometidos en los más diversos ministerios y servicios pastorales y en fos variados campos del quehacer regional.

El primer aspecto que caracteriza a la Iglesia de Temuco, gracias al impulso que le ha dado su actual obispo, es que se percibe claramente como una Iglesia Sinodal. ¿Qué queremos decir? A partir de la concepción de la Iglesia como pueblo de Dios, se quiere expresar que es un pueblo que camina junto a su Pastor (sucesor de los Apóstoles) y un Pastor que camina junto a su pueblo. Este ideal se construye, en la práctica, mediante el impulso de una auténtica pastoral de conjunto, cuyos medios concretos son los siguientes:

- Jornada Diocesana de Pastoral, en la que se recoge el caminar de la Iglesia durante un año y se proyecta el siguiente, fijando las prioridades

Esta visión corresponde a la señalada por el propio obispo monseñor SERGIO CONTRERAS N. al término del II Sínodo Diocesano. "Con Cristo caminamos al Tercer Milenio", nn 22-34. En este punto especifico sobre la visión de la realidad pastoral de la diócesis ha contribuido también el diacono permanente Sr. GUILLERMO DÍAZ CUEVAS, actual Secretario de Pastoral, a quien agradecemos sus valiosos aportes y sobretodo su generosa entrega al servicio de esta Iglesia particular de Temuco.

II Sinodo, 202 
y lineas pastorales que orientarán todo el quehacer evangelizador de la Diócesis.

- Orientaciones Pastorales Diocesanas, fruto de la Jornada anual de Pastoral, en la que el Pastor recoge las voces que vienen desde las Parroquias, Comunidades, Movimientos y Organismos, para plasmarlas en el documento que hace público en la fiesta del 8 de diciembre de cada año.

- Coordinaciones de Areas Pastorales: Eclesial; Agentes Evangelizadores; Pastoral Social. Son concebidas como instancias permanentes para la comunión eclesial. Durante muchos años fueron animadas personalmente por el Pastor. En el último tiempo fue delegando estas coordinaciones a otras personas.

- Visitas Pastorales a Parroquias y Colegios. Son los encuentros que se tienen con el Pastor en cada una de las instancias pastorales mencionadas, en las cuales se utiliza un método participativo que busca potenciar el protagonismo y la corresponsabilidad de los laicos en la misión de la Iglesia.

- Cabe destacar, además, que en cada parroquia existen los Consejos de Pastoral Parroquial y de CEB y Consejos Económicos, a través de los cuales se fortalece la Pastoral de Conjunto y la participación de los laicos.

Especial mención merecen los dos Sinodos Diocesanos que se han realizado en Temuco. El primero se realizó en el año 1968, apenas concluido el Concilio Vaticano II, y fue convocado por el obispo Bernardino Piñera Carvallo. De este Sinodo "surgieron muchas iniciativas que permitieron renovar profundamente la pastoral. Se pasó de una Iglesia estática que todo lo esperaba de los sacerdotes, a una Iglesia dinámica en la que con gran sentido comunitario: sacerdotes, religiosos y laicos, buscaban juntos como mostrar mejor el rostro de Cristo a los hombres del tiempo" ${ }^{38}$

El II Sinodo se realizó durante 1994 y 1995, mediante tres Asambleas precedidas por un largo proceso destinado a recoger desde las CEBs, Parroquias, Colegios y Movimientos todos los aportes que contribuyeron para elaborar los respectivos Documentos de Trabajo. Según la visión del propio obispo:

"el proceso sinodal nos ha permitido un serio diagnóstico de la realidad y una valiosa reflexión de cómo hemos de enfrentarla, en un camino de constante fidelidad a la misión encomendada por el Señor... Se ha expresado claramente el deseo que todo organismo pastoral sea un real servicio a la comunión eclesial y 
para favorecer la pastoral de conjunto dandole a las personas y comunidades un vigor misionero... El Señor nos ha hecho sentir que es muy importante la acción misionera que realizan los laicos en los diversos ambientes; para la cual debe contribuir esa adecuada metodologia de formar que tienen los movimientos apostólicos dando especial atención a la familia y los jóvenes, realizada con definida acentuación en los valores que enseña la Iglesia Católica, pero con actitudes ecuménicas... Se requiere salir al encuentro de todos los sectores sociales: trabajadores urbanos y campesinos: estudiantes universitarios e intelectuales. mujeres dueñas de casa y profesionales; comerciantes y empresarios, y también de los hermanos más postergados de las poblaciones marginales. los enfermos. encarcelados. Cada persona lleva en si una imagen de Jesucristo que hay que revelar en su plena dignidad"."

Otro aspecto muy importante. que en el país resalta como caracteristica de la Iglesia de Temuco, es la de ser una Iglesia encarnada en la realidad social en la cual está inserta, es decir, una Iglesia servidora del mundo. Esto se debe al paulatino desarrolto de una Pastoral Social, que en las diversas y en las más adversas circunstancias históricas. muchos laicos y comunidades cristianas se comprometen en tareas especificas de promoción humana; ellos fueron capaces de asumir esta nueva vertiente de la vida eclesial con mucho entusiasmo y con gran capacidad profesional. Para lograr convierta en servidora de la IX región, la diócesis de Temuco cuenta con los siguientes medios concretos:

- La creación del Departamento de Acción Social como instancia de promoción y coordinación de una gran cantidad de Proyectos de Desarrollo en diversas áreas, tanto del mundo campesino como de las familias de sectores urbanos marginales, constituye una de las primeras grandes decisiones de monseñor Contreras. Con esta acción la Iglesia diocesana toma cada vez más conciencia que la Promoción Humana es parte integrante de la acción evangelizadora de iglesia, porque entre ambas "existen efectivamente lazos muy fuertes", como afirma Pablo $\mathrm{VI}^{40}$

- Como una forma de responder a una problemática concreta se creó durante la dictadura el Comité de Solidaridad, que tenia por objeto salvaguardar y defender los Derechos Humanos y la Dignidad de las personas. Esta es una acción esencial de una Iglesia que se declara servidora de la vida. 
- Los Comedores Infantiles, los grupos de Ayuda Fraterna, los Clubes de Ancianos, los Talleres y Huertos Familiares y las múltiples iniciativas que a través de CARITAS y las mismas Parroquias han permitido a las familias más golpeadas por la pobreza y la miseria resolver parte de sus problemas sociales básicos, como la falta de alimentos y de vivienda, o los problemas derivados de la desocupación y los problemas de salud.

- Especial mención merece la acción pastoral de la Igiesia diocesana en medio del Pueblo mapuche; en este ámbito se desarrolla una autentica Pastoral Social, especialmente a través de la Fundacion Instituto Indigena (fundada en 1962 por Mons. Bernardino Piñera como respuesta a las necesidades de evangelización y desarroilo del Pueblo mapuche) que crea primero los Centros Culturales Mapuches y posteriormente otras iniciativas tendientes ofrecer asesoria para la Defensa de la Tierra y la Cultura Mapuche. En los últimos años se incorpora también la Fundación AFODEGAMA con el objeto de contribuir al desarrollo de los campesinos de origen mapuche.

- Existen, además, otros organismos como la Pastoral de Migraciones que se dedica principalmente a la atención, orientación y acompañamiento de nuestros hermanos migrantes y emigrantes: en su momento este órgano diocesano coordinó las acciones tendientes a acoger a los exiliados y retornados politicos. Por su parte ANECAP (Asociación Nacional de Empleadas de Casas Particulares. fundada en Temuco por monseñor Bernardino Piñera). ha significado un real aporte en cuanto a la capacitación y dignificación de la labor que desarrollan las empleadas de casas particulares.

- Seguramente hay otros organismos e iniciativas que por la extensión de este articulo no han sido expuestos aqui. pero que han significado un aporte importante a la pastoral social de la diócesis, algunos de los cuales se han hecho autónomos y contribuyen decididamente al desarrollo humano de la región.

- Finalmente diremos La Fundación Frontera ha dado origen a diversos proyectos, entre los cuales se cuenta la Universidad Católica de Temuco.

Por último. un tercer aspecto que es absolutamente prioritario e ineludible ya que se trata de una caracteristica esencial de la Iglesia de Jesucristo. es su carácter misionero. La Iglesia centrada en la persona de Jesucristo debe ser siempre misionera: "Desde el comienzo la comunidad eclesial aparece señalada por el imperativo misionero recibido del Señor: "Me ha sido dado todo poder en el cielo y en la tierra. Id. pues y haced discipulos a todas las gentes... (Mt 28,18-19)"." La misma creación de la diócesis de Temuco -como hemos visto- y todo su posterior desarrollo es 
fruto de una acción misionera. "La Diócesis de Temuco debe mucho a la acción realizada por misioneros venidos de otros paises; tanto en el campo de la misión con el pueblo mapuche, como en la atención de parroquias, educación. salud, etc. Son muchos los sacerdotes, religiosos y religiosas, que dejando su patria lo arriesgaron todo por la tarea del Reino".

Los medios concretos que hacen posible que en la diócesis de Temuco exista una acción misionera permanente son fundamentalmente:

- La Misión del obispo con los Seminaristas que cada año se realiza en alguna parroquia que la solicita expresamente. Esta actividad cumple una doble finalidad; en primer lugar, es ciertamente una acción misionera de magnitud, en la que se fortalecen las comunidades cristianas de la parroquia donde se realiza la misión. Sin embargo, lo más relevante es la propia experiencia misionera de los seminaristas, quienes reciben directamente del obispo las orientaciones para una efectiva labor misionera. Los sacerdotes recordamos esta experiencia como una auténtica "práctica profesional", porque en ella aprendimos a ser misioneros y a valorar la actividad misionera como una acción permanente de la Iglesia.

- Fruto del II Sinodo y como una forma de aplicar sus conclusiones, se realizó en la diócesis una Gran Misión Diocesana, entre 1997 y 1999. Fue también la manera como esta Iglesia particular se preparó para celebrar en comunión con la Iglesia universal el Gran Jubileo del Año 2000.

- Producto de la conciencia misionera, que es cada vez mayor en nuestra diócesis, el obispo ha creado el Ministerio Laico para la Animación Misionera. Este ministerio se suma a los ya existentes (ministro Animador de CEB, ministro de la Palabra, ministro extraordinario de la Comunión, ministro Coordinador de Catequesis, de la Pastoral Juvenil, etc.) y ha sido recibido con gran alegria por las comunidades que comienzan a formar sus ministros para la acción misionera.

\section{C. ¿QUiÉn ES EL OBISPO Y CUÁl ES LA MISIÓN QUE LE CORRESPONDE DESARROLLAR EN LA IGLESIA?}

\section{La figura y el rol del obispo en la Iglesia}

No cabe duda que la mayoria de las personas comprenden que el obispo es una figura importante en la vida de la Iglesia, pero ¿en qué radica precisamente su importancia y cuál es su rol especifico? Del griego episkopos, significa literalmente "inspector", "guardián" o "vigilante". Para la 
Iglesia los obispos son los sucesores de los Apóstoles, que en virtud de su consagracion sacramental ejercen el triple ministerio de Cristo: de enseñanza, de santificación y de gobierno. El oficio de enseñar está relacionado con el ministerio de la Palabra y la predicación del Evangelio, porque el obispo es el primer catequista y educador de la fe; el oficio de santificar se relaciona con los Sacramentos, porque el obispo con la gracia que le confiere el sacerdocio de Cristo es el principal liturgo y administrador de los misterios de Dios en la Iglesia; y el oficio de regir y guiar al pueblo de Dios se relaciona con el ejercicio de la autoridad, a ejemplo de Jesús Buen Pastor quien "no vino a ser servido sino a servir" (cf Mt 20,28; Mc 10,45), porque el obispo está enviado a presidir la Iglesia que se le ha encomendado como su primer servidor, mediante lo que comúnmente se denomina la "caridad pastoral".,

Es importante señalar que cada obispo mediante el ejercicio del ministerio pastoral que realiza en la Iglesia particular que le ha sido encomendada "ejerce potestad propia", es decir, un obispo diocesano no actúa por delegación de otro obispo (como un arzobispo, por ejemplo) ni siquiera por el Papa ${ }^{44}$ Por ello, como lo expresa el Concilio Vaticano II, cada obispo es principio y fundamento de unidad para la Iglesia universal, ${ }^{4.7}$ al edificar su Iglesia particular el obispo contribuye a la edificación y desarrollo de toda la Iglesia. En tal sentido, la comunión de los obispos entre si y con el sucesor de Pedro, constituye la garantia de la comunión en toda la Iglesia, como tambièn el mayor testimonio de unidad ante el mundo: "Todos los Obispos, como miembros del Cuerpo episcopal, sucesor del Colegio de los Apóstoles, han sido consagrados no solo para una diócesis determinada. sino para la salvación de todo el mundo" ${ }^{46}$

La comunión es la forma más apropiada para que la Iglesia realice su misión en el mundo. por eso Jesús pidió que sus discipulos vivieran la unidad como caracteristica testimonial ${ }^{1 \%}$. En esta misión los obispos adquieren un rol fundamental. Este principio de unidad de la Iglesia en torno al ministerio episcopal es también una de las ideas claves en los escritos de los Padres. San Ignacio de Antioquia, quien como obispo, no sólo es sucesor de los Apóstoles sino que además se le considera "eco de los apóstoles" porque vivió en una época cercana a ellos, recomienda a las

\footnotetext{
43 Sobre estos aspectos se puede profundizar en la Constitución dogmatica sobre la Iglesia del Concilio Vaticano II: sobre el oficio de enscnar: $L G$ 25, sobre el oficio de santificar: $L G$ 26: sobre el oficio de regir: $L G 27$. LG 27. El Concilio afirma expresamente que los obispos "no deben considerarse como vicarios de los Romanos Pontifices, ya que ejercen potestad propia".

"Los obispos son el principio y fundamento de unidad en las iglesias particulares a ellos confiadas, a base de las cuales sc constituyc la lglesia universal" LG 23; cfr DP 645 .

AG 38

Jesús pidiỏ al Padre por sus discipulos "que vivan unidos para que ol mundo crea" (Jn 17, 21).
} 
comunidades cristianas vivir en unidad y armonia con su obispo, con un efectivo amor fraterno:

"Por tanto, os conviene correr a una con la voluntad del obispo. lo que ciertamente hacéis. Vuestro presbiterio. digno de fama y digno de Dios, está en armonia con el obispo como las cuerdas de la citara. Por ello. Jesucristo entona un canto por medio de vuestra concordia y de vuestra armoniosa caridad. Cada uno de vosotros sea un coro para que. afinados en la concordia a una con la melodia de Dios, cantéis al unisono al Padre por medio de Jesucristo para que os escuche y reconozca, por vuestras buenas obras, que sois miembros de su Hijo." ${ }^{4 \mathrm{H}}$

También San Cipriano, de quien se dice que él mismo ha sido una de las figuras de obispo más notables que ha tenido el cristianismo, enseña que el episcopado es clave para mantener la unidad de la Iglesia:

"Quien no mantiene esta unidad de la Iglesia, ¿cree que mantiene la fe?... Esta unidad debemos mantenerla firmemente y defenderla sobre todo los obispos. que somos los que presidimos en la Iglesia, a fin de probar que el episcopado mismo es también uno e indiviso... El episcopado es uno sólo. del cual cada uno participa solidariamente con los demás. Y la Iglesia es una sola, aunque se extiende ampliamente, formando una multitud, debido a su reciente fecundidad.".9

Sin embargo, respecto al ser y sobre todo a la misión del obispo, no está todo dicho. El documento de trabajo de la $\mathbf{X}^{\mathbf{a}}$ Asamblea Ordinaria del Sínodo de los Obispos expresa que a partir del Concilio Vaticano II se plantea la necesidad de reflexionar permanentemente $y$ en profundidad acerca de 'una nueva valoración de la figura, de la función y de la autoridad del obispo'. Se trata de descubrir "una figura de obispo, conforme al rostro de comunión de la Iglesia, que el mismo Concilio habia puesto a la luz apelando al misterio de la comunión trinitaria como su origen último y modelo trascendente.".

Aunque parezca demasiado evidente, es necesario señalar que un obispo, por sobre todo, es un ser humano y un creyente. Como discipulo de Cristo ha sido elegido no para ostentar un puesto de privilegio en la comunidad eclesial, sino para constituirse en el primer servidor de sus hermanos. Alguien que desde su propia experiencia de fe y de seguimiento de Jesús de Nazaret se com-padece y se com-promete con la humanidad. es decir, que se alegra con las alegrias de los hombres y se entristece con

IGNACIO DE ANTIOQUIA. Epistola a los efesios. 4

SAN CIPRIANO, La Unidad de la Iglesia, 4-6.

50 Lineamenta. El Obispo Servidor del Evangelio de Jesucristo para la Esperanza det Mundo. Ciudad del Vaticano, 1998, n 6; cfr nn 7-9. 
sus dolores. Por eso podemos afirmar con toda certeza que el obispo está llamado a reproducir en su propia persona la imagen de Jesús, Buen Pastor (Jn 10, 11ss), que siente com-pasión de las multitudes desorientadas, cansadas y extenuadas que peregrinan "como ovejas sin pastor" (cfr. Mt 9 . 36).

Precisamente por ello, y por la importancia que adquieren los obispos en la vida de la Iglesia, el citado documento vaticano afirma que ellos "deben asumir esta tarea en primera persona": y como tal, son quienes mejor representan la imagen de una Iglesia servidora del mundo, comprometidos especialmente en la defensa de la dignidad y en la promoción integral del hombre. Por eso al obispo se le considera un ministro del Evangelio para la esperanza del mundo. siguiendo el lema que tan apropiadamente se ha elegido para la $X$ Asamblea (El Obispo. servidor del Evangelio de Jesucristo para la esperanza del mundo). Es el primer servidor que como Cristo compromete su vida hasta entregarla, como expresión máxima de su fidelidad al ministerio episcopal:

"La historia de la Iglesia está poblada de figuras de obispos que, por la fuerza del imperativo que deriva de su misión episcopal, se han empeñado profundamente en la promoción y en la defensa valiente de la dignidad humana... Tales figuras no pertenecen solamente a épocas pasadas. sino también a nuestros dias. Además, el testimonio de sangre de alguno de ellos está depositado en el corazón de sus Iglesias particulares y de la iglesia universal... Su sacrificio, unido al de muchos fieles, a la vez que actualiza y alarga el martirologio de una Iglesia que, al final del segundo milenio"se ha convertido nuevamente en Iglesia de los mártires" (TMA, 37), muestra eficazmente que el mensaje social del Evangelio no es una teoria abstracta sino una vida que se entrega"."

\section{Los Obispos de la Iglesia de Temuco ${ }^{52}$}

Hasta hoy la diócesis de San José de Temuco cuenta con una nómina de seis obispos que la han presidido. El primero de ellos fue un padre redentorista, monseñor Prudencio Contardo Barra, quien ya se desempeñaba como Gobernador Eclesiástico de esta zona desde 1918. Asumió el 3 de mayo de 1926. Presidió la iglesia de Temuco hasta 1935. año en que renunció por motivos de salud. Murió en Santiago a la edad de 90 años.

52 Estos datos están tomados de la página Web de la Iglesia de Temuco. cuyos datos corresponden a un trabajo realizado por Monseñor GUIDO RODRIGUE7 LETELIER, a quien agradeccmos su csfuerzo y permanente preocupación por mantener viva la memoria de nucstra Iglesia. 
Desde el año 1935 hasta 1939 gobernó la Diócesis Monseñor Alfredo Silva Santiago. Fue trasladado a la sede de Concepción después del terremoto del 24 de enero de 1939, que devastó la mayor parte de las iglesias de la zona (fue el primer Arzobispo que tuvo Concepción cuando pasó a ser Arquidiócesis el 20 de mayo de 1939). Durante varios años monseñor Silva Santiago fue al mismo tiempo Arzobispo de Concepción y Rector de la Universidad Católica de Chile.

Sólo 14 meses permaneció como obispo de esta diócesis el religioso de los Sagrados Corazones, monseñor Augusto Salinas Fuenzalida (19391941), porque el 9 de febrero de 1941 fue trasladado a Santiago para servir como obispo Auxiliar del Arzobispo José Maria Caro.

En octubre de 1941 tomó posesión de la Diócesis Monseñor Alejandro Menchaca Lira, quien la gobernó hasta diciembre de 1960. Estos 19 años de gobierno fueron muy fecundos. Como obras muy importantes debemos señalar la construcción de la Casa de Ejercicios "Nuestra Señora de Fátima" y la creación de las bases de lo que hoy es la "Universidad Católica de Temuco" ". Por motivos de salud se retiró a Santiago donde falleció en año 1974. Sus restos fueron trasladados a Temuco y descansan en la cripta de la Iglesia Catedral.

En enero de 1961 llegó a Temuco Monseñor Bernardino Piñera Carvallo quien le imprimió a la diócesis un sello apostólico notable. Desarrolló variadas iniciativas apostólicas, algunas de la cuáles se impulsaron desde Temuco y se extendieron a todo el territorio nacional, como por ejemplo los Cursillos de Cristiandad y las Comunidades Eciesiales de Base. A Monseñor Piñera le correspondió participar en el Concilio Vaticano II y ejecutar sus decisiones. Celebró el Primer Sinodo Diocesano. Monseñor Piñera gobernó la diócesis de Temuco por 17 años hasta que se trasladó a Santiago para dedicarse completamente a la tarea encomendada por la Conferencia Episcopal, como Secretario General de la misma. Actualmente es obispo emérito de la arquidiócesis de La Serena, la cual gobernó entre los años 1983 y 1990.

Monseñor Sergio Contreras Navia, actual obispo de Temuco, le ha dado a la diócesis un impulso y un auge pastoral notable, que se traduce en la consolidación de un gran protagonismo laical y un notorio aumento del Clero Diocesano. Sorprende constatar el significativo aumento de agentes pastorales laicos en las más diversas tareas y ministerios que se desarrollan en la diócesis. Ha ordenado 34 sacerdotes y los Diáconos Permanentes, que nacieron en tiempo de Mons. Piñera, superan en número a los presbiteros diocesanos. Durante su gobierno se han creado en la diócesis cuatro nuevas

5 "Su existencia se vincula a la creacion, en 1959. de la Universidad de la Frontera por el Obispo de la Diócesis de entonces. Monseñor Alejandro Menchaca Lira y a su incorporación a la Pontificia Universidad Católica de Chile en el año 1974 como Sede Regional". Estatutos Generales de la UCT. Art. N ${ }^{\circ} 2$. 
Parroquias y el número de Comunidades Eclesiales de Base ha aumentado significativamente.

La construcción de la Iglesia Catedral, el Edificio Pastoral San José y el Monasterio de las Religiosas Carmelitas Descalzas, son parte de las obras materiales realizadas durante su mandato. Sin duda que una obra importante que debe su existencia a monseñor Contreras es la actual Universidad Católica de Temuco. Después de un largo y complejo periodo de negociación con la Pontificia Universidad Católica de Chile y con autoridades politicas y educacionales del pais. con el objeto de crear un nuevo proyecto universitario con "voluntad de ser" y recuperar asi las caracteristicas originales de la universidad creada por el obispo de Temuco en 1959, el 10 de julio de 1991 firmó solemnemente el decreto que daba origen a esta Casa de Estudios superiores. ${ }^{5.4}$

Sin embargo, pienso que la caracteristica que mejor define a nuestro pastor en su servicio a la Iglesia de Temuco es su espiritu misionero y su gran capacidad para lograr que todas las fuerzas vivas de la Iglesia, especiatmente los laicos, asumieran su compromiso evangelizador. Ello se ha visto reflejado en un proyecto pastorai misionero permanente que se va renovando cada año de acuerdo a las Orientaciones Pastorales diocesanas. Estas orientaciones y la conducción permanente que Mons. Contreras ha realizado de todas las áreas pastorales de la diócesis, ha llevado a que la Iglesia de Temuco tome conciencia de la vital importancia que tiene para su misión un trabajo orgánico y coordinado, lo que se suele llamar 'pastoral de conjunto'.

Durante dos periodos se desempeñó como Secretario General del Episcopado Chileno con dedicación y acierto, demostrando su gran habilidad y capacidad para discernir los 'signos de los tiempos' en medio de los grandes problemas por los que atravesaba la sociedad chilena en la década de los 80 . Hasta hoy se le reconoce como uno de los obispos de mayor claridad en su análisis de la realidad nacional. lo que ha significado que se mantenga en la actualidad como miembro del Comité Permanente de la $\mathrm{CECH}$.

En un reciente discurso-testimonio que el alcalde de la ciudad de Temuco pronunció durante un acto de homenaje a monseñor Contreras, que contó con la aprobación de toda la ciudadania, René Saffirio expresa:

"Durante su permanencia en nuestra ciudad, varias generaciones hemos sido testigos de su sabiduria, de la profundidad de sus convicciones, de la fortaleza de su vocación $y$. por sobre todas las cosas, de su inquebrantable espiritu de 
senvicio a los más pobres, a los discriminados, a los perseguidos y al pueblo mapuche...

Merece reconocimiento su tremendo aporte a la promoción y defensa de los derechos de la persona humana...

Ha sido para muchos la compañia sabia en momentos de dolor; la mirada humilde y cálida para aquellos a quienes la vida ha golpeado con mayor fiereza; el consejo certero para enfrentar la inseguridad y el miedo; y la garantia de saber que su casa siempre estuvo y sigue estando abierta para cualquiera que busque consuelo...

Sus permanentes llamados a ser militantes de la reconciliación y la búsqueda de la paz, han dejado en nosotros huellas imborrables. Gran parte de nuestras decisiones en momentos de aflicción y tensión, tienen presentes los llamados de este pastor breve de estatura y gigante de corazón". ${ }^{55}$

\section{El Obispo que esperamos para la Iglesia de Temuco}

Ya lo hemos señalado, cada Iglesia particular tiene su propia identidad, sus características propias que le vienen dadas por su gente y su cultura, su geografia, sus tradiciones, etc. Por lo tanto, al hablar del obispo que esperamos para la Iglesia de Temuco, debemos considerar todos los elementos históricos, culturales, sociales y pastorales que caracterizan a esta Iglesia. Por ello, la principal caracteristica del obispo que esperamos es que conozca o se interese por conocer profundamente la realidad social, cultural y eclesial de esta diócesis. Sólo de este modo podrá compenetrarse verdaderamente e iluminar efectivamente los problemas que hoy estan presentes en la región y que constituyen los desafios pastorales para la Iglesia.

A partir del análisis que en este mismo articulo hemos hecho, se desprende que son dos las realidades que caracterizan y distinguen a nuestra región y que, por lo tanto, el obispo deberá conocer y asumir como desafio pastoral: la realidad de pobreza que afecta a las familias en un porcentaje mayor que en el resto del pais, con todas sus dolorosas consecuencias; y la especial caracteristica de ser una región pluriétnica y multicultural, con la riqueza que ello significa para la sociedad, pero también con las claras consecuencias de sufrimiento y marginación que provoca especialmente en el pueblo mapuche. En este sentido, esperamos un obispo que recoja el mejor testimonio desde Fray Antonio de San Miguel hasta Monseñor Sergio Contreras Navia. 
Un perfecto resumen de las caracteristicas personales que debe tener el obispo que esperamos para Temuco, lo encontramos en la primera Enciclica del Papa Pablo VI, quien como pastor universal revela cuál debe ser la auténtica actitud y el compromiso de los obispos que han sido llamados a ser los pastores y guias de la Iglesia de Jesucristo:

"Desde fuera no se salva al mundo. Como el Verbo de Dios que se ha hecho hombre, hace falta hasta cierto punto hacerse una misma cosa con las formas de vida de aquellos a quienes se quiere llevar el mensaje de Cristo; hace falta compartir $\sin$ que medie distancia de privilegios o diafragma de lenguaje incomprensible- las costumbres comunes, con tal que sean humanas y honestas. sobre todo las de los más pequeños. si queremos ser escuchados y comprendidos. Hace falta, aun antes de hablar. escuchar la voz. más aún. el corazón del hombre. comprenderlo y respetarlo en la medida de lo posible $y$. donde lo merezca, secundarlo. Hace falta hacerse hermanos de los hombres en el mismo hecho con el que queremos ser sus pastores, padres y maestros. El clima del diálogo es la amistad. Más todavia, el servicio. Hemos de recordar todo esto y esforzarnos por practicarlo según el ejemplo y el precepto que Cristo nos dejó (Jn 13, 14-17)" ${ }^{56}$

En general, si consideramos las condiciones humanas, espirituales y pastorales de los obispos que han presidido la Iglesia de Temuco, se comprende que queramos que el próximo también sea uno de los mejores. Es comprensible esperar que el nuevo obispo de Temuco cumpla con todos los requisitos que la propia Iglesia considera respecto al episcopado y que se encuentran sintetizados en el citado documento de trabajo del "Sínodo de los Obispos", especiaimente en lo referente al triple ministerio pastoral de enseñar, santificar y gobernar que son las tres funciones que en conjunto conforman la misión del obispo. ${ }^{57}$

Para este documento lo primordial y más relevante es señalar que el obispo es un miembro del Pueblo de Dios y que en virtud del sacramento recibido está llamado a reproducir la imagen de Jesucristo. Buen Pastor: "el obispo es antes que nada. como todo cristiano. hijo y miembro de la lglesia; con todos los demás fieles él comparte la dignidad insuperable de hijo de Dios para vivirla en la comunion y en espiritu de grata fraternidad".

Desde esta perspectiva, el obispo que esperamos para nuestra diócesis debe ser consciente de la inmensa dignidad de hijo de Dios que le confiere el bautismo y, por lo mismo, capaz de situarse en la Iglesia como servidor del Pueblo de Dios del cual él también forma parte. Esperamos a un 
hermano en la fe, impulsor de la auténtica vida de comunión fraterna que identifica a los discípulos de Cristo. Un obispo es un ministro, es decir, un servidor, un pastor dócil a Palabra de Dios y a los caminos siempre nuevos del Espiritu, pero por sobre todo es un hombre, por eso esperamos que sea sencillo y cercano a la gente, de gran sensibilidad y capacidad para acoger en su corazón a los más desprotegidos y despreciados de la sociedad.

Al obispo, hermano y peregrino como todos los bautizados, se le considera el "hermano mayor" y es precisamente en este sentido que se le reconoce en la Iglesia como maestro, además porque a imagen de Jesucristo se convierte en padre y pastor de su grey. Todo ello indica que el obispo debe guiar la Iglesia que le ha sido encomendada sin olvidar jamás su condición de discípulo de Jesús. De este modo, el ministerio pastoral que desarrollará el obispo en nuestra diócesis se constituirá en testimonio para todos los hijos de esta Iglesia. Es asi como el documento vaticano reconoce que el obispo "es ante los fieles maestro, santificador y pastor, que actua en nombre $y$ en persona de Cristo... se convierte en "padre" precisamente porque es plenamente "hijo" de la Iglesia: el obispo debe armonizar en su propia persona los aspectos de hermano y padre. de discipulo de Cristo y de maestro de la fe. de hijo de la Iglesia y. en cierto sentido, de padre de la misma". ${ }^{59}$

Un último aspecto que ponemos a consideración respecto al obispo que esperamos para guiar la Iglesia de Temuco en los próximos años es que debiera ser un ministro del Evangelio con una clara convicción de que "su servicio no está restringido exclusivamente a la atención pastoral de los fieles de su Iglesia particular"," sino que debiera considerar todos los ámbitos de la realidad. como por ejemplo el diálogo interreligioso y, desde una perspectiva profética. la preocupación por los grandes problemas del mundo contemporáneo y de la sociedad en la cual vivimos; ámbos elementos forman parte de la misión evangelizadora de la Iglesia. ${ }^{\text {th }}$ Además este es un aspecto que reviste gran importancia dadas las caracteristicas culturales y sociales de la región de la Araucanía

Es indudable que el obispo no solo es importante para la Iglesia católica, sino que es una figura religiosa relevante para la sociedad en su conjunto. Por ello, en relación al diálogo interreligioso, se espera que posea gran disposición y capacidad para establecer relaciones basadas en ef mutuo conocimiento $y$ en el respeto reciproco con aquellos grupos y personas que mantienen una religión y una fe distinta a la nuestra. En el ámbito de la realidad social, ya que la Iglesia no puede mantenerse al margen de los problemas de la vida social, esperamos un obispo capaz de

59 Idem

(i) Lineamenta 72

6) Recomendamos la lectura del capitulo IV del documento vaticanos que estamos comentando. especialmente los números 75 a 85 . 
interpelar esta realidad a partir de la fuerza siempre nueva del Evangelio; con capacidad para aplicar en cada situación concreta los principios orientadores y los criterios de juicio provenientes de la Doctrina Social de la Iglesia y alzar la voz especialmente alli donde esté comprometida la dignidad y los derechos elementales del ser humano.

Nos asiste la convicción de que al exponer las características del obispo que esperamos para nuestra diócesis no estamos pidiendo un imposible. Los chilenos somos testigos de que el Señor suscita para su Iglesia pastores auténticos que saben escuchar, orientar y guiar con sabiduria y sencillez al pueblo de Dios. Como los hubo ayer, también hoy existen en la Iglesia ministros del Evangelio dóciles al Espiritu, que conocen bien la realidad y saben interpretar los signos de los tiempos. Es verdad que el obispo cumple en la Iglesia un rol central y le imprime su sello caracteristico a partir de su carisma personal, pero también es cierto que cada Iglesia particular tiene su propia identidad a partir de la diversidad de carismas que el Espiritu suscita en ella; en este sentido, una Iglesia particular puede también "hacer al pastor" y la experiencia de esta diócesis constituye un buen material para ello.

\section{Un hermano del Papa en Capitan Pastene}

Entre los aspectos que nos interesa resaltar de la historia del Papa Pio XI es la relacion que tiene con nuestra propia realidad, a traves de un hecho poco conocido: dentro del territorio que comprende la nueva Diócesis de San José de Temuco que el mismo Papa creó en aquel octubre de 1925. vivian y viven hasta hoy famiitares suyos. Entre las familias de colonos italianos que llegaron a esta regiór y fundaron la conocida localidad de Capitan Pastene, en la comuna de Lumaco, se encontraba una familia de apellido Ratti, compuesta por don Cipriano Ratti, hermano del Obispo de Roma. De este modo, podemos decir que hubo un Papa en la Iglesia que tenia su famitia en Capitán Pastene. en la Drocesis de Temuco. La familia de don Cipriano Ratti. aunque no llego junto a las demás familias italianas porque a la techa ya se encontraba viviendo en Valparaiso. se traslado a Capitán Pastene y contribuyo al desarrollo cultural de la naciente comunidad

Al crear la diocesis de Temuco. ¿sabria el Papa que su hermano residente en Chile vivia exactamente en el territorio que comprendia esta nueva diocesis? La verdad es que es dificil dar respucsta a esta interrogante porque lamentablementc esła historia no csta exenta de incertidumbres y no tiene, como podria suponerse. un final teliz. La última noticia que los familiarcs de don Cipriano tiener de él es que cuando el cardenal Achille Ratti fuc elegido sucesor de san Pedro quiso que su herniano volviera a Italia: y asi sucedió, Lo extraño es que su familia nunca más supo de èl. Hasta hoy no se sabe si efectivamente !legó a Roma para reunirse con su hermano Papa y se quedó definitivamente en Italia, o si tuvo algun inconvenicnte que le impidió llegar a destino: lo único cicro es que jamás regreso a Chile. ni se comunico con su esposa e hijos que quedaron viviendo definutivamente en Capitản Pastene.

Asi nos cuenta su experiencia un descendiente (bisnicto) del hermano del Papa, el profesor Hernan Benedetti Ralti:

"Segun to que cuenta mi mama. Cipriano Rattillego a Casablanca (Valparaiso) entre los años 1880 y 1890 con su mujer Maria Maga y sus hijos Gioconda y Fermando (en Chile nacio mi "nonno" Juan, en 1894). Se supone que su venida a Chile se debe a que habria tenido afgun problema de caracter politico en thalia (to que nunca pudo ser prccisado porque cn casa los aduftos cuando hablaban de este tema in hacian "sotto voce"!

Por una antigua fotografia familiar. Cipriano habria sido director de ima filamonica en Forino. Se comprende, entonces, que los empresarius de ta colonia de Capitan Pastene quc inicialmente se denominó "Nueva italia" lo contrataran con of fin de elevar el nivel cultural do la misma: y tambicn como famifia suplente para completar la cuota de familias exigidas en ef contrato por parte det [stado clisteno. Cipriano Ratti se desempeño como profesor de música y creador de la banda de músicos (compuso muchas obras para la banda). 
Misteriosamente (no se sabe con exactitud cuando) se fue de Capitan Pastene con su hija Gioconda thay indicios de que volvio a Casablanca. ya que existe un documento notarial su hijo Juan para casarse. ya que era menor de edad). Su rastro se pierde definitivamente en Peumo, desde donde segun to que como familia sabemos- unos curas enviados por su hermano Papa se to habrian llevado a Italia' Quedaron en Capitan Pastene su seriora y sus hijos Femando y Juan éste último continuaria con la obra de su padre en to que respecta a la música. la banda y composiciones musicales.

Además. en relación con su hermano Papa. segun un libro que contiene la biografia de Pio Xl y que se encuestra en mi poder, no aparece por ninguma parte un hermano Cipriano, to que confirmaria el rumor de ser un personaje con problemas politicos y ef biografo del Papa to dejo fuera para no comprometer la imagen de Pio XI. Se hace mencion de los siguicntos tamiliares: su padre Francesco. su madre Teresa Galti. Su hermana Camitla y su hemano Formo. un tio Damiano y dos sobrinos: Luisa y Franco. Sin embargo en ina parte del texto se percibe claramente la existencia de tres hermanos, además de la hermana. Scgun esto. es claro que los hermanos son los siguientes: Fermo. Achilte. ¿Cipriano? y la hermana Camilla". "*

Hasta aqui el relalo que representa de buena forma los sentimientos y la experiencia de la familia Ratti en lorno al tema. "* Personalmente he leido el libro que menciona el profesor Benedetti y es efectivo que el autor desconoce intencionalmente la existencia de Cipriano. Cuando se refiere a los hermanos del Papa habla de "el hermano" y "la hermana"; mientras que en la página citada por el profesor el texto hace referencia a un poema cscrito por el propio Papa. en el cual describe a cada uno de los miembros de su familia y en ese contexto ol autor se refiere expresamente a "los tres hermanos y la hermana".

Debido al analisis somero de los acontecimienlos señalados aqui. estimamos que seria interesante profundizar sobre este hecho histórico que no tiene precedentes en nuestro pais: y estoy cierto que tambien para la propia familia Ratti seria muy valioso conocer más antecedentes sobrc los vinculos de su familia con el Papa Pio XI, de modo que queda planteada la posibilidad de una investigación en torno a este caso.

- En 1904-5 llego a la zona casi un centenar de familias italianas. provenientes de la región EmiliaRomagna, las que fundaron la colonia denominada 'Nueva Italia' (hoy Capitan Pastene) en el corazón de la Araucania

* El libro al que se refiere el profesor Benedetti es de CARLO CONFALONIERI, PIo XI visto da vicino. Ed Paoline. 1993, p. 108. El autor fue secretario del papa duranle el liempo de su pontificado (19221939).

Hay que decir que para los descendientes del hermano del Papa que debieron permanecer definitivamente en Chile los acontecimientos que conforman esta historia no son del todo gratos: a algunos les ha afectado incluso su vinculación con la Iglesia. No es este el caso del profesor Benedetti. quien en la actualidad se desempeña como presidente del Consejo Económico de la Parroquia de Capitán Pastene. Existe, además, una religiosa franciscana que también es descendiente de don Cipriano Ratti. la Hna. Gioconda Cartes Ratti. 
